\title{
Commentary
}

\section{Results without a Negotiated Agreement in Mediation: IUF v PepsiCo, Inc.}

By Yvonne Erkens, Associate Professor of Labor Law, Leiden University, the Netherlands

\section{Introduction}

The National Contact Point of the United States for the oECD Guidelines for Multinational Enterprises (USNCP) received a complaint from the International Union of Food, Agricultural, Hotel, Restaurant, Catering, Tobacco and Allied Workers' Associations (IUF), a global federation of trade unions, that between 5 January and 30 April 2013 all but eight of the 170 workers employed at three Bengal warehouses contracted by PepsiCo in a subcontracting relationship were dismissed or compelled to resign for joining a union. ${ }^{1}$ IUF stated that PepsiCo in India contracts for warehouse services with Radhakrishna Food Land Pvt. Ltd. (RKFL), which in turn contracts with Weavings Manpower Solutions. IUF claims that PepsiCo-by this double outsourcing-facilitated abuses of basic worker rights. PepsiCo's contract with RKFL, IUF alleged, included no provisions related to compliance with national and international labor standards. The 162 union members were invited to return to work on the condition that they renounce their union membership.

IUF requested that the USNCP offer mediation to facilitate a resolution that would include the reemployment of twenty-eight workers. PepsiCo argued that it had duly investigated the allegations and had received satisfactory answers to its inquiries. It emphasized that it had neither the ability nor the obligation

1 OECD National Contact Point, United States, Specific Instance between the International Union of Food, Agricultural, Hotel, Restaurant, Catering, Tobacco and Allied Workers' Associations (IUF) and PepsiCo, Inc., Final Statement, 15 April 2016.

(C) ERKENS, 2017 | DOI 10.1163/24056901-00303009

This is an open access article distributed under the terms of the prevailing CC-BY-NC license at the time of publication 
under the Guidelines to require reemployment of workers dismissed by its contractor. Last, it claimed that IUF's true motivation was PepsiCo's refusal to enter a formal global relationship with IUF, thus abusing the Specific Instance process. PepsiCo also noted that the IUF had inappropriately publicized the complaint through social media.

The USNCP offered its services for mediation, which PepsiCo declined. On May 19, 2014, the USNCP then issued a Final Statement. In November 2015, both PepsiCo and IUF returned in good faith to the bargaining table. USNCP therefore renewed its offer of mediation, which took place over three days in February 2016. IUF, PepsiCo, and RKFL participated. Ultimately, however, the parties were unable to bridge their differences.

The USNCP commented on three issues raised in this Specific Instance: supply chain responsibilities, the value of mediation, and confidentiality. The OECD Guidelines are clear that enterprises are responsible for their supply chains and that suppliers are responsible for their own actions. As for mediation as a tool, the USNCP states that the submitter should not start the process by putting a "best and final offer" on the table. A successful mediation may result in a solution that neither party had imagined before entering the process and that improves the situation of both parties. Finally, the USNCP emphasized that NCP procedures provide that parties are expected to strictly respect the confidentiality of all communications during the entire process-from submission of the complaint to issuance of the final decision.

The USNCP recommended that PepsiCo updates its Human Rights Workplace Policy, committing itself explicitly to the oECD Guidelines for Multinational Enterprises and incorporating the human rights and labor chapters of the Guidelines as the standard for PepsiCo activities.

\section{Analysis}

The oECD Guidelines are divided into two parts: Part I includes the Guidelines, Part II includes implementation procedures. These procedures state that adhering countries shall set up National Contact Points (NCPs) to further the effectiveness of the Guidelines. When problems arise in relation to the observance of the Guidelines, the NCP is to help parties resolve them, but only when they address the NCP "in good faith." "Good faith" in this context means responding in a timely fashion, maintaining confidentiality where appropriate, refraining from misrepresenting the process and from threatening or taking reprisals against parties involved in the procedure, and genuinely engaging in the procedures with a view to finding a solution to the issues raised in 
accordance with the Guidelines. ${ }^{2}$ Generally, issues will be dealt with by the NCP of the country in which the issues have arisen. When issues arise from an enterprise's activity that takes place in several adhering countries or from the activity of a group of enterprises based in different adhering countries, the NCPs involved should consult with a view to agreeing on which NCP will take the lead in assisting the parties. ${ }^{3}$ In this case, an incident in India brought PepsiCo to the USNCP.

The most striking aspect of the current case is the allegation that almost all workers employed at three West Bengal warehouses exclusively contracted by PepsiCo were dismissed for exercising their right to join a union and that union members at the warehouses were the subject of harassment, threats, and intimidation. IUF demanded reinstatement of the workers with back pay. PepsiCo responded that it had no ability or obligation under the Guidelines to require a contractor to reemploy workers with back pay.

Since 2011, supply chain responsibility is clarified in paragraph 20 of the Commentary on General Principles. The USNCP emphasized that the local contractor's being responsible for any labor rights violations it commits does not absolve the company contracting it from responsibility to do what it can to keep its supply chain free from such abuses and ensure that such a contracting arrangement does not infringe on worker rights. The Guidelines also imply that a lack of leverage does not justify inaction. Practical limitations may restrict the ability of enterprises to influence the behavior of their suppliers, but these enterprises, according to the USNCP, are expected to influence their suppliers in any way they can, such as through contractual arrangements, voting trusts, and industry-wide collaborative efforts with other enterprises with which they share common suppliers.

Regarding the IUF allegations, PepsiCo reported receiving satisfactory answers to its inquiries of RKFL about the allegations, which could not be substantiated. PepsiCo also reported that Price Waterhouse Cooper audits of RKFL in late 2013 had also revealed no supporting evidence. The workers had been terminated on the basis of a strike deemed illegal, PepsiCo maintained, because the notice required under Indian law had not been given. IUF argued that the audits provided little reassurance about RKFL operations because they were not shared with either IUF or USNCP.

2 Commentary on the Implementation Procedures of the OECD Guidelines for Multinational Enterprises, para. 21.

3 Ibid., paras. 23 and 24. 


\section{Conclusions}

Although PepsiCo initially chose not to enter into mediation, eventually it decided to come to the USNCP table when the parties' own attempts failed.

An advantage of mediation as an enforcement mechanism is that it is low threshold and confidential, which makes it eminently suitable for sensitive matters such as the implementation and compliance of fundamental labor rights in international business and supply chains. In this case, PepsiCo complained that IUF had publicized the complaint on social media. Although the USNCP emphasizes that the parties are expected to strictly respect the confidentiality of all communications throughout the process, it has no objection to parties informing the public that a complaint has been submitted, but does recommend that parties consider whether such an announcement and the way in which it is made might affect the likelihood of successful mediation. Apart from the implications for the mediation process, this liberal attitude raises the question what information can be given when a party does inform the public. The simple announcement that a Specific Instance has been submitted is not especially informative. The dilemma is the extent to which a party can reveal details of the case, given that confidentiality is the standard.

Although the parties did not reach an agreement, the USNCP stated that the process did lead to greater understanding of the Guidelines and will result in a quicker recognition and easier resolution of the issues as described when they arise in the future. This may be the case: PepsiCo has reported that since June 2015, when it launched its Sustainable Supplier Program, 1,765 of its suppliers and contractors have undergone a preliminary risk assessment. It also reported that it is in the process of updating its human rights policy and supplier code of conduct to better communicate the PepsiCo expectation of its suppliers and contractors. Although this is not necessarily a result of the proceedings that took place before the USNCP, a connection is likely.

Consequently, although mediation had failed, PepsiCo took action on a voluntary base. It is not clear whether the process of mediation and negotiation had any concrete positive effects for the dismissed employees. Although the reported results must be welcomed, the announcement of reinstatement or adequate compensation for the concerned workers would have been a real victory. 